\title{
CALIDAD DE LA LECHE CRUDA Y SISTEMA DE PAGO POR CALIDAD EN EL ECUADOR
}

\section{QUALITY OF RAW MILK AND PAYMENT SYSTEM FOR QUALITY IN ECUADOR}

\author{
Rocio Contero $^{* 1} \oplus$, Narcisa Requelme ${ }^{1,4} \oplus$, Charles Cachipuendo $^{2} \oplus$ y Daniel \\ Acurio $^{3}$ (i)
}

${ }^{1}$ Grupo de Investigación de la leche (GILEC). Universidad Politécnica Salesiana, Quito, Ecuador.

${ }^{2}$ Grupo de Investigación en Ciencias Ambientales (GRICAM). Universidad Politécnica Salesiana, Quito, Ecuador.

${ }^{3}$ Grupo de Investigación en Biotecnología Aplicada a los Recursos Naturales (BIOARN), Universidad Politécnica Salesiana, Quito, Ecuador.

${ }^{4}$ Universidad Politécnica de Madrid, Madrid, España.

*Autor para correspondencia: rcontero@ups.edu.ec

\section{Resumen}

Para mantener la salud de la población los Estados legislan la calidad, inocuidad y propiedades nutricionales de los alimentos, regulaciones que se aplican en la producción e industrialización, así, Ecuador implementó una política de mejora de la calidad de la leche cruda a través del precio. .El objetivo del estudio fue determinar el cumplimiento de los parámetros establecidos en el reglamento de pago por calidad de leche (RPCL) cruda bovina vigente en el Ecuador durante el periodo 2009-2018. Se utilizaron $(n=103$ 204) datos obtenidos por el Laboratorio de Calidad de Leche de la Universidad Politécnica Salesiana provenientes de 3 regiones del país. Fueron analizados los parámetros de: grasa, proteína, sólidos totales, contaje de bacterias totales (CBT), conteo de células somáticas (CCS) y se revisaron las diferentes regulaciones ecuatorianas que impulsaron la calidad y productividad de la leche en el periodo de estudio. Los promedios generales fueron: $3,80 \pm 0,05 \%$; proteína $3,12 \pm 0,10 \%$; sólidos totales $12,36 \pm 0,16 \%$. CCS y CBT disminuyeron entre el 2009 y 2018: CCS de $460 \times 10^{3}$ a $447 \times 10^{3}$ células $/ \mathrm{mL}$ y el CBT de 1 millón UFC/mL a promedios entorno a los $200 \times 10^{3} \mathrm{UFC} / \mathrm{mL}$, respectivamente. Se concluye que el RPCL fue positivo para los parámetros de composición con valores sobre los límites establecidos. La calidad higiénica y sanitaria muestran mejoras en el tiempo, aunque CCS no entra en los límites máximos permisibles debido a que implica un abordaje multifactorial de acciones para la mejora.

Palabras clave: Composición de leche, calidad de leche, sistema de pago, contaje de bacterias, células somáticas. 


\begin{abstract}
States legislate quality to maintain the health of the population, safety and nutritional properties of food, regulations that apply on the production and industrialization, thus Ecuador implemented a policy to improve the quality of raw milk through price. This study aimed to determine the compliance of the parameters established in the regulation of payment for quality of raw bovine milk (RPQM) in Ecuador during the period 2009-2018. Total data $(n=103204)$ were obtained by the milk quality laboratory of the Salesian Polytechnic University from 3 regions of the country. The parameters of fat, protein, total solids, total bacteria count (TBC) and somatic cell count (SCC), and the Ecuadorian regulations that promoted the quality and productivity of milk in this study period were analyzed. The general averages were: fat $3,80 \pm 0,05 \%$; protein $3,12 \pm 0,10 \%$; total solids $12,36 \pm 0,16 \%$. SCC and TBC decreased between 2009 and 2018: SCC from $460 \times 10^{3}$ to $447 \times 10^{3}$ cells $/ \mathrm{mL}$ and TBC from 1 million CFU $/ \mathrm{mL}$ to averages around $200 \times 10^{3}$ $\mathrm{CFU} / \mathrm{mL}$, respectively. In conclusion the RPQM was positive for the chemical parameters with values above the limits established. The hygienic quality (TBC and SSC) showing improvements over time although, the SCC does not within the maximum permissible because it implies a multifactorial action for improvement being necessary to concentrate efforts on health and GMP.
\end{abstract}

Keywords: Milk composition, milk quality, payment system, bacteria count, somatic cells.

Forma sugerida de citar: Contero, R., Requelme, N., Cachipuendo, C. y Acurio, D. (2021). Calidad de la leche cruda y sistema de pago por calidad en el Ecuador. La Granja: Revista de Ciencias de la Vida. Vol. 33(1):31-43. http://doi.org/10.17163/lgr.n33.2021.03.

IDs Orcid:

Rocio Contero: http:/ / orcid.org/0000-0001-5335-1283

Narcisa Requelme: http:/ / orcid.org/0000-0002-3877-199X

Charles Cachipuendo: http:/ / orcid.org/0000-0002-7700-7740

Daniel Acurio: http:/ / orcid.org/0000-0002-2305-4349 


\section{Introducción}

Por la importancia de nutrir el organismo y mantener una vida saludable los Estados han visto la necesidad de legislar en defensa de la calidad, inocuidad y propiedades nutricionales de los alimentos (Hoyos y D'Agostini, 2017). Con la revolución industrial surge la necesidad de contar con el control de productos y servicios, pero a partir de 1960 en la jurisprudencia europea surge el Derecho Alimentario, que junto con las normas y reglamentos han logrado armonizar la construcción de disposiciones y métodos para mejorar las relaciones comerciales nacionales e internacionales. Estas regulaciones se impusieron para la producción, industrialización y obtención de alimentos inocuos con protección de la salud del consumidor.

Las políticas agropecuarias en el Ecuador se iniciaron con las reformas agrarias (1950-1978) marcadas por las luchas campesinas, que modificaron la estructura de la propiedad y distribución de tierras. La Ley de Fomento y Desarrollo Agropecuario de 1979 impulsó el Desarrollo Rural Integral donde se generaron las primeras políticas para realizar investigación agropecuaria, asistencia técni$\mathrm{ca}$, abastecimiento de insumos y regulaciones para productos elaborados y procesados (García, Vivanco y Bermeo, 2019; Madrid, 2019). A partir del año 2000, las políticas se centraron en promocionar a la pequeña y mediana industria, y se estandarizaron protocolos para el empaquetado y etiquetado de alimentos de origen agropecuario. En este período llamado posneoliberal surgieron los conceptos de seguridad y soberanía alimentaria, se impulsaron a los negocios inclusivos de productos tradicionales y no tradicionales con fines de exportación, requiriendo el cumplimiento de regulaciones en todos los eslabones de la cadena productiva (Madrid, 2019). Desde el 2007, las políticas y regulaciones fueron orientadas a garantizar los derechos de los consumidores e impulsar la calidad y competitividad en todos los ejes de la producción.

En el marco de la Constitución del Ecuador del 2008 se generó la política agropecuaria 2015-2025, donde se planteó promover el desarrollo rural sostenible, erradicar el hambre y la malnutrición como prioridades. Al mismo tiempo se generaron otras leyes conexas que fueron definiendo las normativas correspondientes y la institucionalidad necesaria para la implementación de las regulaciones (Lasso y Clark, 2016).

La producción de leche en el Ecuador es una de las actividades pecuarias más importantes, su producción es en torno a 5,1 millones L/día proveniente de las tres regiones del país Costa, Sierra y Amazonia (INEC, 2018). Una leche de alta calidad es definida como un alimento de sabor agradable, sin olores, de adecuada composición química, libre de agentes patogénicos y contaminantes (Pereira, 2014; Sah y col., 2018). Los parámetros para determinar la calidad de la leche previa a la industrialización se evalúan a través de análisis físicos, químicos y microbiológicos. Estos parámetros son regulados en todos los países mediante normativas para los procedimientos de colecta, transporte y análisis con leves variaciones en los límites de cumplimiento y métodos empleados (Dürr, Carvalho y Santos, 2004).

Hasta el año 2008, en el Ecuador el precio del litro de leche no dependía de la composición u otros parámetros, sino que era acordado directamente entre industrias y los productores (MAGAP, 2008). La importancia de conocer la calidad de la leche radica en que a partir de ese conocimiento se pueden tomar decisiones que afectarán a la gestión de la producción industrial con el objetivo de optimizarla. En el marco de la política de calidad el 2013, el Ministerio de Agricultura, Ganadería y Pesca del Ecuador (MAGAP) emitió el reglamento de pago por calidad de leche (RPCL) bajo el Acuerdo 394 vigente hasta la fecha, el cual definió el pago por litro en finca, exigiendo el cumplimiento de indicadores de composición, calidad higiénica y sanitaria. Para su ejecución fueron establecidas otras regulaciones conexas y cambios en la institucionalidad estatal.

En este contexto, el objetivo de esta investigación fue determinar el cumplimiento de los requerimientos establecidos en el RPCL en los parámetros de grasa, proteína, sólidos totales, contaje de bacterias totales y conteo de células somáticas durante el periodo 2009-2018, comparando la información disponible por cada región. Además, se plantea analizar las regulaciones y normativas que se emitieron entorno al RPCL para su ejecución e incidencia en los productores, producción y productividad. 


\section{Materiales y Métodos}

\section{$2.1 \quad$ Área de estudio}

El territorio continental ecuatoriano se divide en 3 regiones: Costa, Sierra y Amazonía por factores ambientales determinantes como la presencia de la cordillera de los Andes, la vegetación de la Amazonia y las corrientes del Niño y de Humboldt (IGM, 2017). En cada región el clima varía según la altitud, humedad relativa, precipitación y temperatura. Según el Instituto Nacional de Estadísticas y Censos (INEC, 2018) estos factores inciden también en el volumen de producción nacional y reporta el $23 \%$, $72 \%$ y $5 \%$ para la Costa, Sierra y Amazonia, respectivamente.

\subsection{Datos, colecta de muestras y métodos de análisis de los parámetros de calidad}

Los datos provienen de la base datos del laboratorio de calidad de leche de la Universidad Politécnica Salesiana (UPS). Fueron un total de 99271 (n) análisis solicitados entre años 2009 y 2018 por productores asociados en centros de acopio (CA), tinas comunitarias y fincas particulares con una frecuencia de 1-2 veces/mes. Los datos corresponden a 12 provincias de las 3 regiones del Ecuador. La región Sierra por su importancia en la producción fue dividida en 2, Sierra Norte: Carchi, Imbabura, Pichincha con el 78,9\% $(n=81431)$ y Sierra Centro: Chimborazo y Tungurahua con el 4,7\% $(n=4835)$. La región Costa: El Oro, Esmeraldas, Guayas, Manabí y Santo Domingo de los Tsáchilas con el 9,8\% $(\mathrm{n}=10066)$. La región de la Amazonía: Napo con el $6,7 \%(n=6872)$.

La colecta de muestras siguió los procedimientos de referencia definidos (Cassoli y col., 2007; Cassoli, Machado y Coldebella, 2010), para composición y células somáticas se usaron frascos estériles de $40 \mathrm{~mL}$ con Bronopol y para CBT se utilizó Azidiol. El transporte de muestras se realizaba a temperatura de refrigeración de $4-7^{\circ} \mathrm{C}$. Los valores mínimos exigidos de los parámetros de composición son: grasa, proteína y sólidos totales siendo 3,0\%, $2,9 \%$, y $11,2 \%$, respectivamente (INEN, 2012). Dentro de los parámetros microbiológicos, el conteo de bacterias totales (CBT) tuvo un valor máximo aceptable de hasta $300 \times 10^{3} \mathrm{UFC} / \mathrm{mL}$ (MAGAP, 2013) y el conteo de células somáticas (CCS) un valor máximo de $400 \times 10^{3}$ células $/ \mathrm{mL}$ (Cerón-Muñoz, Agudelo y Maldonado-Estrada, 2007).

La grasa, proteína y sólidos totales fueron analizados por espectrofotometría infrarroja transformada de Fourier (FTIR) con el equipo Milkoscan FT 6000 (Foss Analitical Instruments, Dinamarca) y los resultados se expresaron en valores de porcentaje (g/mL) (Takahashi, 2011). Para la CCS se utilizó un contador electrónico, el Fossomatic minor FC (Foss- Analitical, Dinamarca) basado en citometría de imagen, donde una muestra de leche coloreada emite impulsos luminosos que son ampliados por un fotomultiplicador, contabilizados y expresados los resultados en células $\times 10^{3} / \mathrm{mL}$ (Ramos, 2019).

Para determinar la CBT se utilizó el método de citometría de flujo, con el equipo Bactoscan FC $50 \mathrm{H}$ (Foss Analitical Instruments, Dinamarca), cuyo principio analítico se basa en inyectar una muestra coloreada a través de una cámara de flujo y el sistema óptico detecta a las partículas teñidas por fluorescencia. Los resultados obtenidos son expresados como UFC/mL y representan la cantidad de bacterias aerobias mesófilas presentes en las muestras (Cassoli y col., 2007; Numthuam y col., 2017).

Todos los ensayos fueron sujetos a controles de calidad e intercomparaciones dentro del sistema de gestión de calidad de acuerdo a la Norma ISO17025, 2017. Los métodos de colecta, de análisis y de los equipos utilizados se mantuvieron invariables durante el periodo de estudio evaluado.

\subsection{Análisis estadístico}

Se realizó un análisis descriptivo utilizando el programa estadístico Infostat versión 2018, analizando las variables con respecto a los límites permisibles fijados en la normativa ecuatoriana y comparando la información entre las regiones analizadas.

\subsection{Revisión de regulaciones}

Según información disponible en el MAGAP se analizaron las diferentes regulaciones, instructivos y manuales de procedimientos, entre otra documentación que apoyaron la ejecución del RPCL. 


\subsection{Análisis de la información de producto- res, producción y productividad}

Los productores de leche requirieron modificaciones en sus prácticas de producción e infraestructura para cumplir con las disposiciones del RPCL. Los pequeños productores (<200 L/día) se agruparon formando CA y tinas comunitarias, varios de ellos mantuvieron convenio con la UPS entre 20092018 para el análisis de leche, monitoreo y capacitación en buenas prácticas de ordeño (BPO), y buenas prácticas agropecuarias (BPA). La información sobre producción y productividad fue analizada según los datos del INEC para los mismos años.

\section{Resultados y discusión}

\subsection{Evolución de la calidad composicional}

Los parámetros de composición son influenciados por diferentes factores como la alimentación, genética, raza del animal, período de lactancia, época del año, frecuencia y momento del ordeño (Belage y col., 2017). Cuando la leche tiene mayor concentración de sólidos, esencialmente proteína y grasa, se aportan más nutrientes al consumidor y mejora el rendimiento y la calidad de los derivados lácteos (Barbano, Ma y Santos, 2006; Pereira, 2014). Sin embargo, la relación entre sus componentes es estable y la variación puede ser utilizada como indicador de adulteración. El monitoreo permanente de los indicadores químicos o microbiológicos son esenciales para el establecimiento de cualquier programa de control de calidad (Dürr, Carvalho y Santos, 2004; Johnson, 2017; Takahashi, 2011).

\subsubsection{Grasa}

El contenido de grasa tiende a variar más que otros componentes de la leche. Los principales factores influyentes son la raza, edad, alimentación, estado de lactación, actividad bacteriana en el rumen, mastitis y efectos ambientales (Ramírez-Rivera y col., 2019). Además de la adición de concentrados en la dieta, el tipo, cantidad y tamaño de la partícula de la fibra, también contribuyen con la variación de los porcentajes de grasa en leche.

La grasa está compuesta por un $98 \%$ de triglicéridos y $2 \%$ de diglicéridos, colesterol, fosfolípidos y ácidos grasos libres. La grasa de la leche bovina es una de las más complejas pues posee más de 400 ácidos grasos diferentes que forman los triglicéridos de los cuales, en términos generales el $70 \%$ son ácidos grasos saturados y $30 \%$ ácidos grasos insaturados (García, Montiel y Borderas, 2014; Pereira, 2014; Sah y col., 2018).

El promedio general de contenido de grasa fue $3,80 \pm 0,05 \%$, superior al límite permisible en la norma para todos los años analizados (Figura 1a). Los valores más altos se reportaron para la región de la Costa y Amazonia (3,82 $\pm 0,10 \%)$ donde se mantiene tradicionalmente un ganado de doble propósito (carne y leche) (INEN, 2012; Oñate, 2018). Estos valores se corresponden con los reportados en trabajos similares como el realizado en el estado de Hidalgo, México donde se analizaron 1416 muestras de 3 cuencas lecheras que producían el 3,9\% del total nacional para el año 2010, obteniendo el 3,46 $\pm 0,26 \%$ de grasa butírica clasificando a la leche como tipo A, indicando excelente calidad en este parámetro (Cervantes, Cesín y Mamani, 2013). Guevara-Freire y col. (2019), al trabajar con productores de la Sierra ecuatoriana, reportaron que la alimentación de los hatos basada en gramíneas y leguminosas, así como el uso de concentrados y heno elevaron los porcentajes de grasa. Otro factor influyente fue la raza, principalmente de vacas Holstein y mestizas (criolla $x$ Holstein), que en el sector del estudio, mantuvieron los valores de grasa entre 3,4 a 3,7\%.

\subsubsection{Proteína}

El contenido de proteína en la leche de vaca es importante en la dieta humana ya que aporta entre 30-32 gr/L. Las proteínas solubles son las proteínas del suero como la lactoalbúmina, la lactoglobulina y otras sustancias nitrogenadas no proteicas como la urea que representan el $20 \%$ y las proteínas insolubles representadas por la caseína entre el 78$80 \%$ (Pereira, 2014). Las caseínas por encontrarse formando un sistema coloidal estable con el calcio, fósforo y magnesio favorecen la digestibilidad y el transporte de estos minerales. Funcionalmente, debido a la alta calidad biológica de péptidos bioactivos, las proteínas de la leche aportan a la salud humana ya que favorece la absorción de otros nutrientes (García, Montiel y Borderas, 2014; Sah y col., 2018).

A nivel de industria el porcentaje de proteína 
influye en el rendimiento de los productos procesados, principalmente queso y yogurt, y en Ecuador representan el $41 \%$ de los derivados más consumidos (Alvarado, 2017; Oñate, 2018). Varios factores que influyen en el contenido de grasa tienen también influencia en la composición proteica de la leche como es la nutrición, manejo de enfermedades, estado de lactación y edad de la vaca, así como la estación climática (García, Montiel y Borderas, 2014; Johnson, 2017). Los pastizales comunes utilizados en la región Costa y otros introducidos y mejorados en la región Sierra (Requelme y Bonifaz, 2012) permiten que la proteína se mantenga en valores aceptables de 3,01 a 3,25\%, como en el $70 \%$ de los productores reportados por Valladares (2016).

El promedio general para este parámetro (Figura $1 b$ ) fue entre $3,12 \pm 0,10 \%$ siendo superior al límite permisible en todas las regiones. Los valores más bajos en la Amazonía (3,04 $\pm 0,09 \%$ ) se deben a los diferentes patrones alimenticios, nivel energético y razas de animales que determinan la composición de la leche en este parámetro (García, Montiel y Borderas, 2014). Otro estudio realizado para evaluar las propiedades fisicoquímicas, microbiológicas y toxicológicas en siete cuencas lecheras de la región de Puno en Perú que producen el 7,5\% de la producción del país, encontraron valores de 2,81-3,20\%, que podrían variar por el tipo de alimentación provista, presentando mayores porcentajes por uso de concentrados proteicos derivados de harina de pescado, soya, alfalfa y maíz versus la alimentación por pastoreo (Brousett-Minaya y col., 2015).

En países donde un gran porcentaje de leche se destina a la elaboración de yogurt, quesos y leche en polvo, es importante que el sistema de pago contemple el contenido de proteína, como se reporta en España y Costa Rica (Dürr, Carvalho y Santos, 2004; Martinez y Gomez, 2013).

\subsubsection{Sólidos totales}

En productos alimenticios donde el agua es el componente dominante (83-84\%), se valoran los niveles de extracto de sólidos totales (EST) que corresponden a la suma de grasa, proteína total y verdadera, lactosa y minerales (Ramírez-Rivera y col., 2019).
En el mercado internacional el contenido de EST es uno de los referentes más importantes de calidad láctea, por representar menores costos de deshidratación y mayor conversión del producto terminado para la industria (Barbano, Ma y Santos, 2006). Los sistemas de producción, a más de incrementar la productividad, deben tener como objeto obtener leche con mayor cantidad de sólidos totales. Los criterios para maximizar el contenido de EST deben basarse en un adecuado y eficiente balance de nutrientes en las raciones alimenticias, maximización del consumo de alimentos, monitoreo periódico de la dieta y correcciones periódicas por cambios cuantitativos y cualitativos de los recursos utilizados. Para algunos autores el aumento en la producción de leche se refleja en la dilución de los sólidos totales, como grasas, proteínas y sólidos no grasos (Ramírez-Rivera y col., 2019).

En todas las regiones los valores de EST fueron $12,36 \pm 0,16 \%$ superiores al límite permisible y correspondiente a una leche de buena calidad (Figura 1c). En la región Sierra Centro resaltan los menores promedios $(12,27 \pm 0,22 \%)$, versus la Región Sierra Norte, esto se explica porque las provincias del norte iniciaron programas de capacitación técnica impulsados por el Estado y entidades privadas (Vinueza, 2015).

Estos valores son similares con los presentados en el departamento de Sucre-Colombia trabajando con 12 municipios, donde se evaluó la calidad composicional e higiénica de la leche en épocas de verano e invierno, obteniendo valores promedio de 12,79 y $13,11 \%$ respectivamente e indicando una leche de alta calidad. Esta tendencia puede explicarse por la predominante presencia de razas cebuínas con cruces entre Bos taurus y Bos Indicus que, al tener un menor volumen de producción láctea, concentran más los sólidos presentes (Martinez y Gomez, 2013). En Ecuador también se reporta ganado cebuíno principalmente en la Costa, pero también se presentan cruces de animales criollos con razas Brahman, Charolaise y Holstein. En la Sierra, la mayor parte del ganado se ha mejorado con cruzamientos de Holstein, Brown Swiss y Jersey (Requelme y Bonifaz, 2012). 

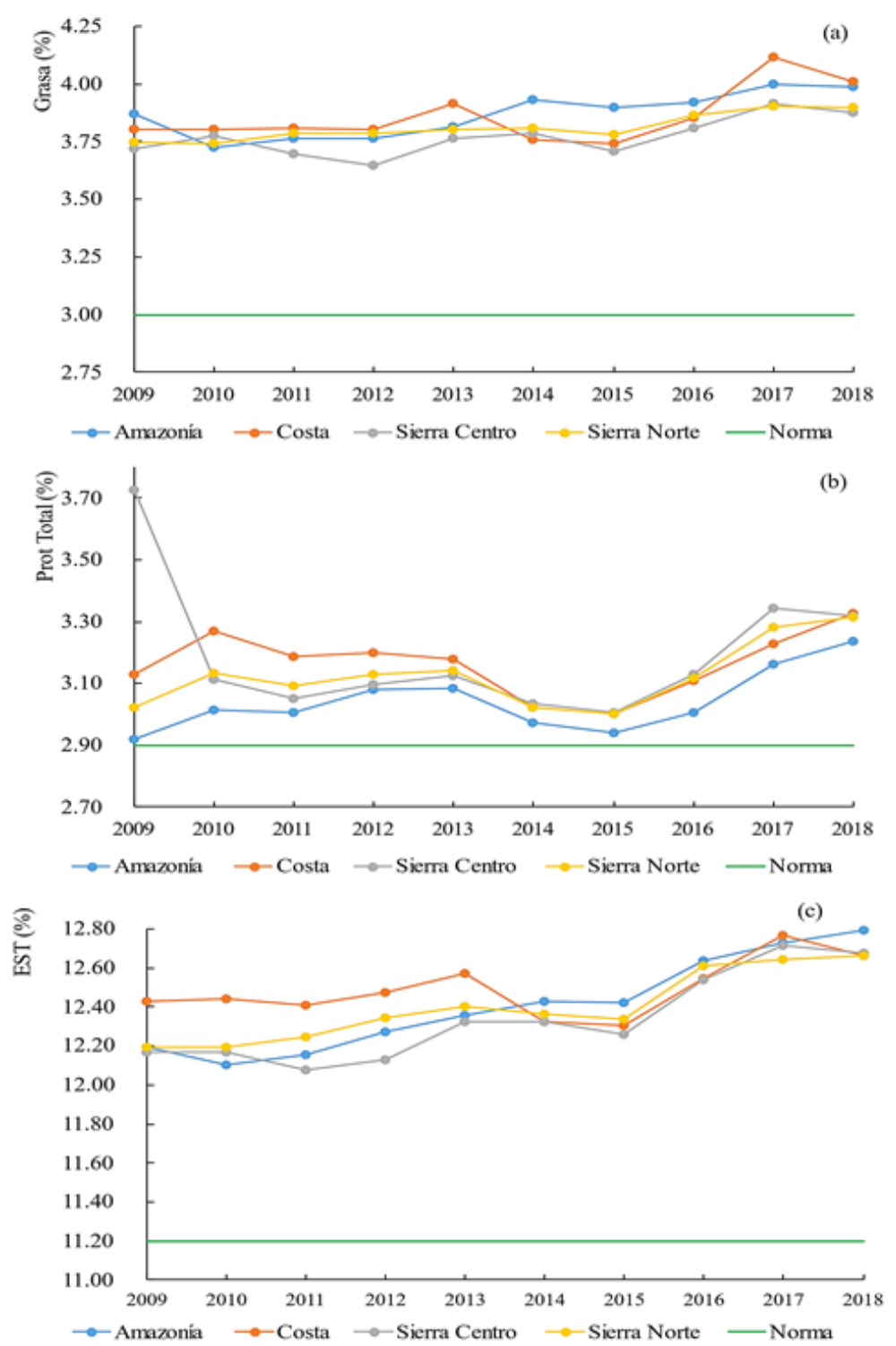

Figura 1. Parámetros de composición de la leche en porcentajes durante el periodo de estudio: (a) grasa (b) proteína (c) sólidos totales.

\subsection{Evolución de la calidad sanitaria e hi- giénica}

\subsubsection{Contaje de células somáticas}

Las células somáticas (leucocitos, predominantemente neutrófilos y células epiteliales) son un indicador de la salud de la glándula mamaria y por tanto de la calidad de la leche. Un aumento de células somáticas puede ser indicador de procesos inflamatorios por respuesta de la fagocitosis. Los factores que elevan el CCS pueden ser los períodos de posparto, el número de lactaciones, agentes físicos o químicos irritantes en las ubres, entre otros, por tanto la detección temprana del incremento de estos valores es clave para el control (Carloni y col., 2016; Gonçalves y col., 2018).

Los valores de CCS en casos de ausencia de infección mamaria oscilan entre $200-300 \times 10^{3}$ células $/ \mathrm{mL}$, mientras que los recuentos $>800 \times 10^{3}$ 
células/mL suelen estar asociados a procesos inflamatorios persistentes. Aunque el CCS no se encuentra incluido en el actual RPCL del Ecuador, para este estudio se tomará como límite $400 \times 10^{3}$ células $/ \mathrm{mL}$, valor estandarizado en varios países del mundo especialmente en la Unión Europea y Brasil asociado con hatos que poseen BPA (Cerón-Muñoz, Agudelo y Maldonado-Estrada, 2007; MAPA, 2011).

Los resultados de este estudio (Figura 2a) destacan un período común de descenso del CCS en todas las regiones partiendo de un valor promedio de $460 \times 10^{3} \pm 118$ a $447 \times 10^{3} \pm 32$ células / / mL para el 2009 y 2018, respectivamente. En el año 2018 las regiones Sierra Norte, Sierra Central y Amazonía presentaron valores $<400 \times 10^{3}$ células $/ \mathrm{mL}$ y la región de la Costa presentó un valor mayor a $500 \times 10^{3}$ células $/ \mathrm{mL}$.

En una investigación realizada en 7 provincias del Ecuador el $90 \%$ de los productores manifestaron conocer la importancia de realizar la limpieza de ubres previo el ordeño y el secado pero solo el $65 \%$ de los encuestados aplicaban una prueba de rutina para control de mastitis (Bonifaz y Requelme, 2011; Guevara-Freire y col., 2019). Por lo anteriormente señalado, era necesario definir las condiciones de manejo, producción y nutrición del ganado para el cumplimiento del RPCL en el Ecuador.

\subsubsection{Contaje de bacterias totales}

Desde el punto de vista bacteriológico, una buena calidad de leche es esencial para obtener productos de buena calidad, siendo el CBT es el parámetro más frecuentemente utilizado como referente (Martinez y Gomez, 2013). En Ecuador, como en otros países de Latinoamérica, hasta el 2008 eran solo utilizadas las pruebas de acidez titulable y reductasa (azul de metileno) para la determinación indirecta de la carga bacteriana. Por esta razón, fue necesario incorporar sistemas más sensibles y rápidos con tecnologías modernas para determinar este parámetro dentro del RPCL.

Las exigencias internacionales son cada vez mayores, para los CBT en Europa y USA se acepta un valor máximo de $100 \times 10^{3} \mathrm{UFC} / \mathrm{mL}$ y $300 \times 10^{3}$ $\mathrm{UFC} / \mathrm{mL}$, respectivamente. El RPCL para el 2008 definió un límite de $600 \times 10^{3} \mathrm{UFC} / \mathrm{mL}$, lo cual seguramente influyó en los productores en la disminución de los promedios, de aproximadamente 1 millón UFC / mL a $800 \times 10^{3} \mathrm{UFC} / \mathrm{mL}$ para el 2011 y 2012. La Sierra Centro se mantiene con valores promedios de 1,5 millones UFC/mL hasta el 2013, calificando a la leche de mala calidad; pero a partir del año 2014 los promedios descienden y desde el 2015 son de $<400 \times 10^{3} \mathrm{UFC} / \mathrm{mL}$. Aunque para los años 2016 y 2017 los CBT suben en el promedio general $\left(>500 \times 10^{3} \mathrm{UFC} / \mathrm{mL}\right.$ ) para el 2018 descienden nuevamente a $200 \times 10^{3} \mathrm{UFC} / \mathrm{mL}$ calificando a la leche como de buena calidad. Es importante reiterar que estos datos corresponden a productores formales $(98,6 \%)$ que mantienen compromisos contractuales continuos con las industrias (Figura 2b).

Estos resultados son similares a los reportados al analizar 10704 muestras de leche colectadas entre 1993 y 2009 en tambos de la zona noroeste de Santa Fe y sur de Santiago del Estero en Argentina y mostrando promedios de CBT $<100 \times 10^{3} \mathrm{UFC} / \mathrm{mL}$ observando una significativa mejora por los procesos de capacitación y gestión de productores incluidos en el programa de mejoramiento integral de calidad de leche, entre productores, empresarios y el Estado (Revelli, Sbodio y Tercero, 2011).

\subsection{Regulaciones públicas entorno al RPCL}

Cuando se establece un sistema de pago por calidad es importante contar con un diagnóstico previo y definir un plan por etapas (Dürr, Carvalho y Santos, 2004). Sin embargo, en Ecuador el primer RPCL emitido por el Decreto ejecutivo 1042 (MAGAP, 2008), se definió basándose en estándares internacionales adaptados. La iniciativa de regular la comercialización de la producción de la leche con exigencia de la calidad fue una estrategia para lograr su establecimiento. En este decreto, el precio del litro de leche se incrementó y se fijó en 0,35 USD si cumplía los limites descritos en la norma INEN 009 para los requisitos físico-químicos y microbiológicos de leche cruda. Además, también se incorporaron los criterios de bonificación por cumplimiento de los requisitos sanitarios del ganado (vacunación y BPO). 

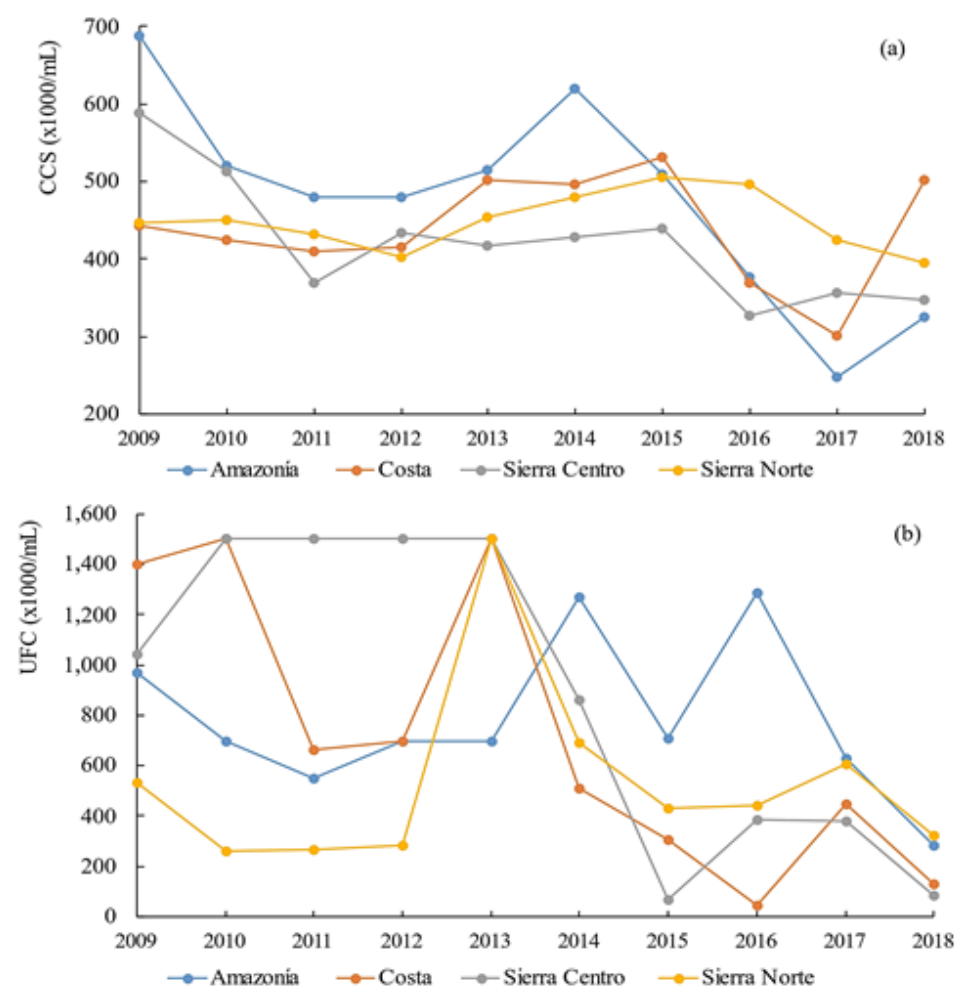

Figura 2. Parámetros microbiológicos de la leche durante el periodo de estudio: (a) Contaje de células somáticas (células $\times 10^{3}$ células $/ \mathrm{mL})$; (b) Contaje de bacterias totales $\left(\times 10^{3} \mathrm{UFC} / \mathrm{mL}\right)$.

Para el año 2010 (Tabla 1), se realiza una modificación al acuerdo ministerial 394 (MAGAP, 2010), donde se indexa el precio de litro de leche en finca al 52,4\% del PVP de la leche UHT, impuesto en el mercado debido a la extensión de su larga vida en percha por ultrapausterización. Para el año 2013, el actual RPCL (MAGAP, 2013), fijó el precio base del litro de leche (0,42 USD) y aplicó la bonificación de calidad sanitaria y BPA.

La implementación del RPCL fue acompañada por la reorganización de instituciones estatales y sus funciones, así, la Agencia Ecuatoriana de Aseguramiento de la Calidad del Agro (AGROCALIDAD) conjuntamente con el MAGAP, se encargó del sistema de seguimiento y evaluación de las cadenas de producción agropecuaria (Agrocalidad, 2017). Al ser el manejo nutricional del ganado y la sanidad de las ubres factores influyentes en los indicadores de calidad, se estableció la Guía de BPP y los procedimientos de la vigilancia sanitaria. Esta resoluciones fueron difundidas entre el 2010-2013 en procesos de capacitación como las Escuelas de la Revolución Agraria (ERA's) y otros procesos impulsados por entidades privadas como universidades y distribuidores de insumos agropecuarios (Derks y col., 2014; FAO, 2011; Vinueza, 2015).

Otro aporte también importante para establecer el RPCL fue la certificación de laboratorios para la verificación de los parámetros de calidad, que hasta el año 2008 eran ejecutados por las mismas industrias (Alvarado, 2017; MAGAP, 2008). El disponer de laboratorios especializados para estos servicios tiene varias ventajas porque centraliza la inversión en el personal, la infraestructura y la tecnología, y se optimiza el uso de equipos con capacidad de realizar un alto número muestras (Dürr, Carvalho y Santos, 2004). 
Tabla 1. Principales resoluciones que apoyaron el establecimiento del RPCL en el Ecuador.

\begin{tabular}{|c|c|c|}
\hline Año de emisión & Descripción & Referente a: \\
\hline 23/04/2008 & Acuerdo $N^{\circ}$ 077-MAG. Decreto Ejecutivo 1042 & $\begin{array}{l}\text { Reglamento para normar el pago por calidad } \\
\text { de leche y sanidad animal }\end{array}$ \\
\hline $21 / 04 / 2010$ & Acuerdo Ministerial MAGAP $N^{\circ} 136$ & $\begin{array}{l}\text { Precio mínimo de sustentación del litro de leche } \\
\text { al productor indexado en el } 52,4 \% \text { al precio de venta } \\
\text { al público (PVP) de leche fluida UHT en funda. }\end{array}$ \\
\hline $04 / 09 / 2013$ & Acuerdo Ministerial MAGAP $N^{\circ} 394$ & $\begin{array}{l}\text { Regular y controlar el precio del litro de leche cruda } \\
\text { pagado en finca y/o centro de acopio y promover la } \\
\text { calidad e inocuidad de la leche cruda. }\end{array}$ \\
\hline $30 / 06 / 2015$ & $\begin{array}{l}\text { Resolución } N^{\circ} 16 \text {. } \\
\text { Modifica resolución } N^{\circ} \text { DAJ-2013461-0201.0213 }\end{array}$ & $\begin{array}{l}\text { Especificaciones técnicas para los centros de acopio } \\
\text { y transporte de leche. }\end{array}$ \\
\hline 29/02/2016 & $\begin{array}{l}\text { Resolución } N^{\circ} 19 \text {. } \\
\text { Modifica la resolución } N^{\circ} 217\end{array}$ & $\begin{array}{l}\text { Guía de buenas prácticas pecurias de producción de } \\
\text { leche. Se exige un plan anual de manejo sanitario. }\end{array}$ \\
\hline $15 / 04 / 2016$ & Resolución $N^{\circ} 71$ & $\begin{array}{l}\text { Instructivo para el registro y control de laboratorios } \\
\text { de análisis de leche cruda. }\end{array}$ \\
\hline $15 / 08 / 2016$ & $\begin{array}{l}\text { Resolución } N^{\circ} 154 \text {. } \\
\text { Modifica la resolución } N^{\circ} \text { DAJ-2013461-0201.0213 }\end{array}$ & $\begin{array}{l}\text { Manual de procedimientos para la vigilancia y control } \\
\text { de la inocuidad de leche. }\end{array}$ \\
\hline $30 / 01 / 2017$ & Resolución $N^{\circ} 276$ & $\begin{array}{l}\text { Guía de buenas prácticas pecuarias en ganadería de leche } \\
\text { para pequeños productores. Establece sistemas de seguimiento } \\
\text { y evaluación en la cadena de producción agropecuaria de leche. }\end{array}$ \\
\hline $30 / 08 / 2017$ & $\begin{array}{l}\text { Resolución } N^{\circ} 95 \text {. } \\
\text { Modifica resolución } N^{\circ} \text { DAJ-2013461-0201.0213 }\end{array}$ & $\begin{array}{l}\text { Manual de procedimientos para la vigilancia y control } \\
\text { de la inocuidad de leche. }\end{array}$ \\
\hline
\end{tabular}

\subsection{Impacto en los productores, produc- ción y productividad}

A partir del año 2001, la formación de CA de leche comunitarios fue un importante acontecimiento en Ecuador que marcó el inicio de la comercialización de leche con refrigeración por parte de los pequeños productores y la decadencia de la recolección de leche y venta por parte de intermediarios informales (Oñate, 2018). Entidades públicas y privadas canalizaron ofertas de crédito y programas de asistencia técnica, inversión en infraestructura para compra de equipos para enfriamiento, adquisición de fertilizantes, implementos de ordeño, vacunas, entre otros (Valladares, 2016). Desde el 2013 se han ejecutado varios programas y proyectos para apoyar a los CA, reducir los costos de producción y promover una producción más limpia (Valladares, 2016).

La producción de leche en Ecuador para el año 2009 fue 6249 785,0 L/día (INEC, 2019). En los años siguientes se presentaron incrementos $\mathrm{y}$ bajas, y en especial, desde el año 2013 hasta el 2018 se observó una tendencia negativa (Figura 3a). Sin embargo, la productividad tuvo un incremento a nivel nacional (6,12 a 7,03 L/vaca/día), siendo la región Sierra la de mayor incremento con 7,2 a 8,3 L/vaca/día (Figura 3b). Se puede asumir que la producción decreció debido a dificultades de los pequeños productores para implementar y cumplir las disposiciones del RPCL. Para el año 2017, el número de miembros en los CA disminuyó (36\%) con respecto a los registrados para el 2008 y esto puede explicarse porque algunos productores abandonaron los CA y otros volvieron a entregar la leche a un intermediario para evitar directamente la relación con el CA y las exigencias de calidad (Alvarado, 2017).

Cabe mencionar que el 18\% de los productores eran personas $>61$ años de edad, lo que se traduce en un escenario negativo para la adopción de "nuevos" procedimientos como el uso de desinfectantes para el pre y post ordeño, el uso de papel industrial para limpiar las ubres, entre los principales (Nuñez, 2017; Oñate, 2018; Valladares, 2016).

Para mejorar la productividad en el periodo de estudio existieron fuertes inversiones en la instalación de sistemas de riego comunitarios, mejorando el uso eficiente del agua a nivel de parcela e incrementando la materia seca en la alimentación del ganado (Cachipuendo y col., 2017), así como el uso de semillas mejoradas de forrajes adaptadas a tecnologías locales y mejoramiento genético del ganado (Requelme y Bonifaz, 2012). 

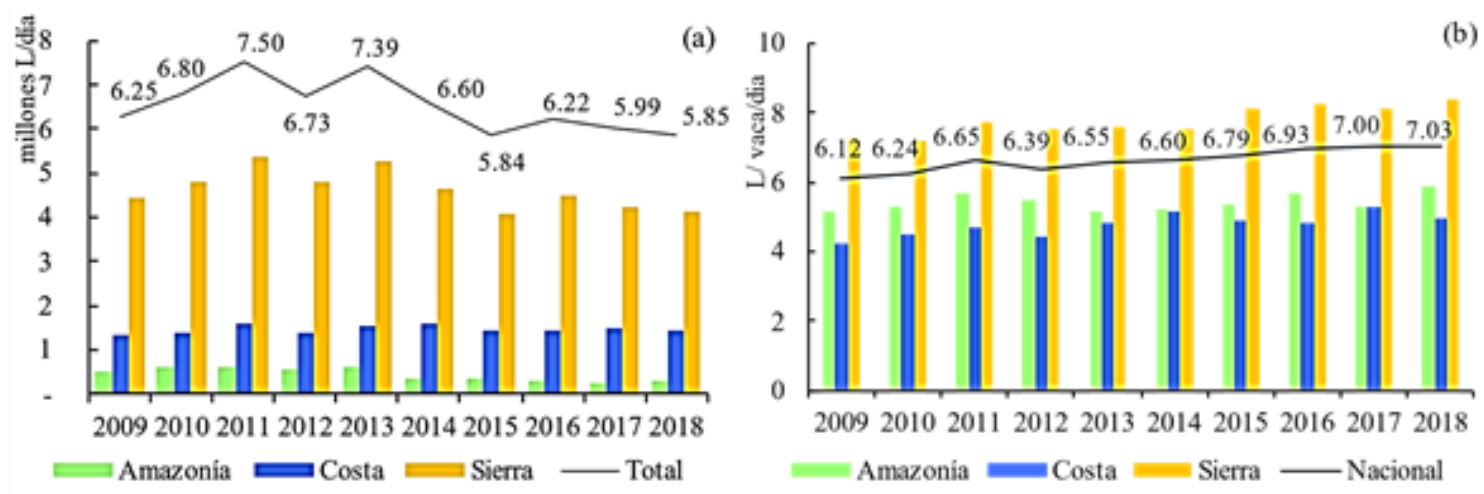

Figura 3. Producción y productividad de la leche por regiones del Ecuador: (a) producción en millones de L / día y (b) productividad L x vaca x día (INEC, 2019).

\section{Conclusiones}

El establecimiento del RPCL y las políticas aplicadas durante el periodo 2009-2018 tuvieron un efecto positivo sobre los parámetros de calidad, mismos que cumplen los límites establecidos, no así en la producción que tiene tendencia a la baja.

Los parámetros de composición grasa, proteína y sólidos totales se han mantenido dentro de los límites permisibles y se verifica una tendencia a la mejora a lo largo de los años. Los parámetros sanitarios e higiénicos (CCS y CBT) también muestran mejora en el tiempo, siendo el CCS el que aún no entra dentro de los límites máximos permisibles, dado que implica un abordaje multifactorial de acciones para su mejora; por lo tanto, es necesario concentrar esfuerzos en la sanidad y aplicación de BPO en las ganaderías de leche.

El establecimiento de los sistemas de pago por calidad de leche debe estar acompañado por programas de capacitación y gestión entre productores, industrias y el Estado.

\section{Agradecimiento}

Los autores agradecen a las empresas lácteas, en particular a Ecuajugos S.A., industrias lácteas, centros de acopio de leche y productores por permitir utilizar la información de la base de datos de la UPS para la publicación de este artículo.

\section{Referencias}

Agrocalidad (2017). Programa de certificación, seguimiento y recertificación de unidades de producción en Buenas Prácticas Agropecuarias a nivel nacional. Coordinación General de Inocuidad de Alimentos Dirección de Inocuidad de Alimentos.

Alvarado, R. (2017). Estudio de mercado "Sector de la leche en el Ecuador". Superintendencia de control del poder de Mercado. Ecuador.

Barbano, D., Y. Ma y M. Veiga dos Santos (2006). «Influence of raw milk quality on fluid milk shelf life». En: Journal of dairy science 89, E15-E19. Online:https:/ / bit.ly/2LZbYvN.

Belage, E. y col. (2017). «The Canadian National Dairy Study 2015-Adoption of milking practices in Canadian dairy herds». En: Journal of dairy science 100.5, 3839-3849. Online:https: / / bit.ly / 3s2IJHR.

Bonifaz, N. y N. Requelme (2011). «Buenas prácticas de Ordeño y la Calidad higiénica de la leche.» En: La Granja 14.2, 45-57. Online:http: / / bit.ly / 3dCB3bn.

Brousett-Minaya, M. y col. (2015). «Physicochemical, microbiological and toxicological quality of raw milk in cattle basins of the region PunoPerú». En: Scientia Agropecuaria 6.3, 165-176. Online:https:/ / bit.ly/3u7L1Ya.

Cachipuendo, C. y col. (2017). «Uso comunitario del agua y del suelo para la producción sustentable de pasturas». En: La Granja 26.2, 106-118. Online:https://bit.ly/2NfmLCM.

Carloni, E. y col. (2016). «Effect of farm characteristics and practices on hygienic quality of ovine raw milk used for artisan cheese production 
in central Italy». En: Animal Science Journal 87.4, 591-599. Online:https:/ / bit.ly/3ayX60U.

Cassoli, L., P. Machado y A. Coldebella (2010). «Métodos de conservação de amostras de leite para determinação da contagem bacteriana total por citometria de fluxo». En: Revista Brasileira de Zootecnia 39.2, 434-439. Online:https: / / bit.ly / $3 \mathrm{k} 4 \mathrm{mtuE}$.

Cassoli, L. y col. (2007). «Correlation study between standard plate count and flow cytometry for determination of raw milk total bacterial count». En: International Journal of Dairy Technology 60.1, 44-48. Online:https://bit.ly/2NagWXn.

Cerón-Muñoz, M., E. Agudelo y J. MaldonadoEstrada (2007). «Relationship between individual and bull tank somatic cell counts with CMT test in two dairy herds in Antioquia (Colombia)». En: Revista Colombiana de Ciencias Pecuarias 20.4, 472-483. Online:https:/ / bit.ly/3qtNwBP.

Cervantes, F., A. Cesín e I. Mamani (2013). «La calidad estándar de la leche en el estado de Hidalgo, México». En: Revista mexicana de ciencias pecuarias 4.1, 75-86. Online:https://bit.ly/2ZrA3Pb.

Derks, M. y col. (2014). «Associations between farmer participation in veterinary herd health management programs and farm performance». En: Journal of Dairy Science 97.3, 1336-1347. Online:https://bit.ly/3au8x9Y.

Dürr, J., M. Carvalho y M. Santos (2004). O compromisso com a qualidade do leite no Brasil. UPF.

FAO (2011). Buenas prácticas de ordeño. 1. ${ }^{\mathrm{a}}$ ed.

García, C., R. Montiel y T. Borderas (2014). «Grasa y proteína de la leche de vaca: componentes, síntesis y modificación». En: Archivos de zootecnia 63, 85-105. Online:https://bit.ly/37svHeQ.

García, D., N. Vivanco y J. Bermeo (2019). «Evaluación económica del sector agropecuario e industrial en Ecuador 1980-2015». En: ECA Sinergia 10.2, 116-128. Online:https:/ / bit.ly/3uehrQE.

Gonçalves, J. y col. (2018). «Bovine subclinical mastitis reduces milk yield and economic return». En: Livestock Science 210, 25-32. Online:https: / / bit.ly/3beUzrE.

Guevara-Freire, D. y col. (2019). «Calidad de leche acopiada de pequeñas ganaderías de Cotopaxi, Ecuador». En: Revista de Investigaciones Veterinarias del Perú 30.1, 247-255. Online:https:/ / bit.ly / 3dsRhno.

Hoyos, C. y A. D'Agostini (2017). «Segurança alimentar e soberania alimentar: convergências e divergências». En: Revista NERA 35, 174-198. Online:https:/ / bit.ly/3rZm8fo.

IGM (2017). Atlas Rural del Ecuador. Ed. por Instituto Geográfico Militar. Primera. Quito: Journal of Chemical Information y Modeling.

INEN (2012). Norma técnica ecuatoriana. Leche cruda. Requisitos. NTE INEN. Instituto Ecuatoriano de Normalizació.

Johnson, M. (2017). «A 100-Year Review: Cheese production and quality». En: Journal of Dairy Science 100.12, 9952-9965. Online:https:/ / bit.ly/ 3qyOugh.

Lasso, G. y P. Clark (2016). «Soberanía alimentaria, modernización y neodesarrollismo: las contradicciones de la política agraria en el Ecuador de la Revolución Ciudadana». En: La Revolución Ciudadana En Escala de Grises Avances, Continuidades y Dilemas, 260-291. Online:https:/ / bit.ly / 2M84A1o.

MAGAP (2008). Decreto Ejecutivo No 1042. Reglamento para normar el pago por calidad de la leche y sanidad animal. Acuerdo ministerial 077.

- (2010). Acuerdo ministerial 136.

- (2013). Acuerdo ministerial 394. Regular y controlar el precio del litro de leche cruda pagado en finca $y / o$ centro de acopio al productor y promover la calidad e inocuidad de la leche cruda.

MAPA (2011). Instrução normativa 51: parâmetros e exigências do mercado. Inf. téc. Ministerio de Agricultura e Pecuaria- Brasil.

Madrid, T. (2019). «La política agraria en Ecuador (1965-2015).» En: Rev. Econ. 70, 89-120. Online:http:/ / bit.ly/37BVy4k.

Martinez, M. y C. Gomez (2013). «Calidad composicional e higiénica de la leche cruda recibida en industrias lácteas de Sucre, Colombia». En: Biotecnología en el sector Agropecuario y agroindustrial 11.2, 93-100. Online:https://bit.ly/2M85Z8a.

Numthuam, S. y col. (2017). «Method development for the analysis of total bacterial count in raw milk using near-infrared spectroscopy». En: Journal of Food Safety 37.3, 1-7. Online:.

Nuñez, E. (2017). «Caracterizaciín de la asociaciín de pequeños productores de leche y su aporte al desarrollo local: caso Gualea, parroquia rural del distrito metropolitano de Quito». Tesis. Quito: Universidad Central del Ecuador.

Oñate, J. (2018). «Cadena agroalimentaria de la leche vacuna en Ecuador y sus potencialidades exportadoras . Periodo 2008-2015». Tesis. Quito: Pontificia Universidad Católica del Ecuador. 
Pereira, P. (2014). «Milk nutritional composition and its role in human health». En: Nutrition 30.6, 619-627. Online:https:/ / bit.ly/3s4LJDC.

Ramírez-Rivera, E. y col. (2019). «Tropical milk production systems and milk quality: a review». En: Tropical Animal Health and Production 51.6, 1295-1305. Online:https://bit.ly/2Nlildt.

Ramos, A. (2019). "Contagem de células somáticas em leite de búfalas usando um classificador.» Tesis de mtría. Universidad Federal da Bahia.

Requelme, N. y N. Bonifaz (2012). «Caracterización de sistemas de producción lechera de Ecuador». En: La Granja 15.1, 55-69. Online: https:/ / bit.ly / 3avqJjx.

Revelli, G., O. Sbodio y E. Tercero (2011). «Estudio y evolución de la calidad de leche cruda en tambos de la zona noroeste de Santa Fe y sur de Santiago del Estero, Argentina (1993-2009)». En: Revista de Investigaciones Agropecuarias 37.2, 128-139. Online:https:/ / bit.ly/3k0OgMi.
Sah, B.N.P. y col. (2018). «Antioxidative and antibacterial peptides derived from bovine milk proteins». En: Crit Rev Food Sci Nutr. 58.5, 726-740. Online:http:/ /bit.ly/2ZFV08X.

Takahashi, F. (2011). «Aplicação do controle estatístico de processo (CEP) como ferramenta para a melhoria da qualidade do leite». Tesis de mtría. Universidade de São Paulo.

Valladares, S. (2016). «Determinación del impacto de la política de precios por calidad del litro de leche en los centros de acopio del norte del cantón Cayambe Periodo 2008-2014». Tesis de Maestria. Universidad de las Fuerzas Armadas del Ecuador.

Vinueza, G. (2015). «Evaluación de las escuela de la revolución agraria (Eras's) en el fomento de la agricultura sostenible en la provincia de Imbabura». Tesis de maestria : Agricultura Sostenible. Universidad de las Fuerzas Armadas del Ecuador. 